\title{
Agôn
}

Revue des arts de la scène

Critiques | Saison 2015-2016

\section{Ça ira (1) Fin de Louis, de Joël Pommerat}

De l'étrange familiarité de l'histoire

\section{Caroline Mounier-Vehier}

\section{(2) OpenEdition \\ Journals}

Édition électronique

URL : http://journals.openedition.org/agon/3980

DOI : 10.4000/agon.3980

ISSN : 1961-8581

Éditeur

Association Agôn

Référence électronique

Caroline Mounier-Vehier, "Ça ira (1) Fin de Louis, de Joël Pommerat », Agôn [En ligne], Critiques, mis en ligne le 12 mars 2016, consulté le 23 septembre 2020. URL : http://journals.openedition.org/agon/ 3980 ; DOl : https://doi.org/10.4000/agon.3980

Ce document a été généré automatiquement le 23 septembre 2020

Association Agôn et les auteurs des articles 


\title{
Ça ira (1) Fin de Louis, de Joël Pommerat
}

\author{
De l'étrange familiarité de l'histoire
}

Caroline Mounier-Vehier

\section{RÉFÉRENCE}

Ça ira (1) Fin de Louis - spectacle de Joël Pommerat, compagnie Louis Brouillard - créé en septembre 2015 au Manège de Mons dans le cadre de Mons 2015-Capitale européenne de la culture.

1 Chaque spectacle de Joël Pommerat peut donner le sentiment de découvrir le nouvel espace d'un univers déjà familier. Ce n'est pourtant pas le cas de Ça ira (1) Fin de Louis. S'il s'agit toujours pour le metteur en scène d'interroger notre société et notre rapport au monde, ce spectacle témoigne cependant de nouvelles recherches dramaturgiques et esthétiques, qui permettent de poser autrement les mêmes questions, notamment en s'inscrivant dans un nouveau rapport à l'histoire. Alors que Ma Chambre froide ou La Réunification des deux Corées mettaient en scène des personnages confrontés aux difficultés d'une vie ordinaire, régie par des préoccupations du quotidien, Ça ira (1) Fin de Louis s'intéresse à la grande histoire en représentant le début de la Révolution française. Toutefois, ce spectacle ne nous donne pas à voir un épisode historique lointain, grandiose et stupéfiant, mais nous invite à nous réapproprier notre histoire. Dès le début de la représentation, des débats naissent sur des sujets qui résonnent avec le contexte politique et économique actuel : il est question de crise économique, de réformes fiscales, de privilèges et de misère. Comment ne pas penser à notre époque en écoutant des nobles arrogants s'efforçant de protéger leurs privilèges au détriment du bien commun? Comment ne pas y penser aussi devant des hommes et des femmes réduits à la misère et prêts à se révolter pour obtenir la justice qu'on ne leur rend pas ?

L'ensemble du spectacle repose sur un équilibre étrange entre distance et proximité. Désigné par son seul prénom, Louis XVI semble plus familier et proche de nous, homme 
autant que roi. La reine, quant à elle, ne correspond ni au personnage historique de Marie-Antoinette, ni à sa légende, noire ou dorée. Elle aussi nous apparaît comme plus proche. Qu'il s'agisse du choix des costumes, ou encore d'une conversation téléphonique du roi avec le pape ou d'une journaliste espagnole venue faire un reportage télévisé pour son pays, divers anachronismes émaillent le spectacle. Ces allusions au contexte historique sont imprécises et on ne reconnaît que de loin certains événements et acteurs de l'époque. Des choix qui créent, paradoxalement, une impression de proximité avec les personnages : ils sont comme nous et, parce que nous ne savons rien de précis à leur sujet, tout ce qui pourrait nous les rendre étrangers est atténué. Joël Pommerat fait le choix de nous rendre proche la Révolution française, non pas en nous rappelant précisément les chiffres, les noms, les dates. Il entend plutôt nous la donner à voir de l'intérieur, en cherchant moins le vrai que le vraisemblable. Nous accédons ainsi à une forme d'expérience intime de l'histoire telle que les hommes pourraient la vivre et la faire. Ses précédents spectacles offraient des expériences semblables, mais la perspective est ici inversée : l'histoire du quotidien a laissé place à la grande histoire, sur laquelle nous pensons si rarement pouvoir agir.

Or, nous pouvons et devons agir, et c'est de cela dont témoigne l'organisation spatiale $\mathrm{du}$ spectacle. Contrairement aux dispositifs circulaire et bifrontal expérimentés par Pommerat dans d'autres spectacles, la frontalité permet ici de souligner l'appartenance à une même société. Les acteurs, remarquables de présence et d'efficacité, y contribuent en se mêlant au public et en jouant avec lui. Il ne s'agit pas de maintenir les spectateurs dans une situation d'observateurs fascinés et impuissants, mais au contraire de leur donner le sentiment d'être partie prenante de la représentation. Or, cela correspond à une inflexion sensible du rapport qu'entretient le théâtre de Joël Pommerat aux questions politiques. En effet, la place des spectateurs, au cœur du dispositif scénique, met en évidence leur place au cœur de la société et l'importance de leur rôle de citoyens. Dans ce spectacle, ils ne sont pas seulement des observateurs : ils sont invités à se sentir concernés par le monde dans lequel ils vivent, et à en être les acteurs. 